organisation. Our study concerned safety and health culture assessment in 600 companies of the private sector in Côte d'Ivoire. Preliminary results for 151 companies were presented in the present communication and concerned sectors of transport, manufacturing, construction and publics work, forest exploitation and sawmills.

Methods A descriptive cross-sectional study was conducted from November to December 2016 in 151 companies. But, since all companies having more 100 workers in Côte d'Ivoire are concerned, soapproximately 6600 workers will be includedat the end of our study. For the 151 companies, 1661 workers were questioned about their opinion on the implementation level in their companies of prevention culture pillars as confirmed at the 2nd Strategic Conference of Dresden (Germany, 2011) and leading role criteria as defined in 2012 by the Agency European for OSH. In addition, professional and sociodemographic characteristics of workers have been noted.

Results Results, covering 151 companies, indicated that $70 \%$ of the workers $(n=1661)$ affirmed effective implementation of the prevention culture in their companies. About the pillars of the prevention culture, $68 \%$ of workers affirmed occurrence of reducing work accident and occupational diseases scheme in their companies, 55\% for the OHS training program and $51 \%$ for the program of cooperation between public health and OSH. According to the leading role, 51\% of workers affirmed relatively high $\mathrm{OSH}$ prevention policy in their companies. However, in the manufacturing sector $(n=58)$, prevention policy is inadequate in $44 \%$ of cases and completely nonexistent in $23 \%$ of cases.

Conclusion Taken together, in contrast to the positive perception of workers, our results suggested an insufficient implementation of safety and health culture in the 151 companies.

\section{OCCUPATIONAL ACCIDENTS: THE REALITY OF NURSING WORKERS A BRAZILIAN UNIVERSITY HOSPITAL} 'Mirian Cristina dos Santos Almeida, ${ }^{2}$ Cristiane Helena Gallasch*, Kátia Pontes Remijo',
${ }^{1}$ Carolina Luiza Bernardes, 1 'Vinicius Gomes Barros, Bárbara Marques Anginoni', Patrícia
Campos Pavan Baptista'. 'University of São Paulo,São Paulo, Brazil; ${ }^{2}$ Rio de Janeiro State
University, Rio de Janeiro, Brazil

\subsection{6/oemed-2018-ICOHabstracts.841}

Introduction It is known that the work process in hospital nursing job, when developed under adverse conditions, can result in an increased occurrence of occupational accidents and/or processes of wear.

Objective To monitor nursing workers' occupational accidents in an university hospital.

Method It is an exploratory study, developed in the hospital of the University of São Paulo, in 2016, after Research Ethics Committee - School of Nursing of the University of São Paulo approval (\#1110/2011). Data were extracted from the software SIMOSTE ${ }^{\circledast}$ - Monitoring System for Nursing Workers' Health, and studied using descriptive analyses with SPSS ${ }^{\circledast}$ 20.0 .

Results The mean age of the 77 nursing workers that notified occupational accidents is 43.3 years old $(S=9.4)$; $80.5 \%$ of them are women. About nursing categories, $67.5 \%$ are auxiliary or technicians and $32.5 \%$ are nurses (RN). The locations with the highest occurrence of occupational accidents were: Intensive Care Units (24.7\%) and emergency service (20.8\%). Most of work notifications was typical accidents (77.9\%), followed by the disease (11.7\%) and route accidents (10.4\%). Analysing the occupational accidents according to the International Statistical Classification of Diseases and Related Health Problems (ICD-10), it was found greater occurrence of injuries to the wrist and hand - S60-S69 (22.1\%); knee and lower leg injuries - S80-S89 (10.4\%); and ankle and foot injuries S90-S99(10.4\%). About workloads, the mechanic aspects were involved in $77.9 \%$ of occupational accidents, followed by biological (27.3\%). In general, the occupational accidents caused 85 days of removal from work.

Conclusions The occupational accidents occurred more frequently in nursing technicians, involving mainly mechanic and biological workloads. Traumas of upper and lower limbs were the most common. The monitoring of occupational accidents can provide subsidies for interventional measures of prevention of diseases and health promotion, and consequently a reduction in absenteeism.

\section{NECESSARY COOPERATION IN OCCUPATIONAL HEALTH AND SAFETY IN NORTH AFRICA FRENCH SPEAKING COUNTRIES}

Abdeljalil El Kholti. Occupational Health Unit, Faculty of medicine, Hassan II University of Casablanca, Morocco

\subsection{6/oemed-2018-ICOHabstracts.842}

Aim of special session Demonstrate ways of current collaboration in occupational safety and health, and, explore innovative ways for promoting collaboration in this field.

Co-Chair: Mr Stéphane Pimbert

INRS - Franc

Prof Bennaceur BENALI ${ }^{(1)}$, Mr Stéphane PIMBERT ${ }^{(2)}$, Dr Halim HAMZAOUI ${ }^{(3)}$,

Prof Rafik GHARBI ${ }^{(4)}$, Prof Abdeljalil EL KHOLTI ${ }^{(1)}$, Dr Mounia El Yamani ${ }^{(5)}$

(1) Occupational Health Unit, Faculty of Medicine and Pharmacy, University Hassan II of Casablanca, Morocco

(2) General Director, INRS, Paris, FRANCE

(3) OSH specialist for North Africa- ILO office for MAGHREB Algiers

(4) Head of Industrial toxicology research lab, Faculty of medicine of Tunis, Tunisia

(5) French Agency for Public Health, Department of Occupational Health, Saint Maurice, France

(6) MOHA: Moroccan Occupational Health Association

\section{1a COOPERATION IN THE FIELD OF OCCUPATIONAL HEALTH AND SAFETY IN NORTH AFRICA}

B Benali. Occupational Health Unit, Faculty of Medicine and Pharmacy, University Hassan II of Casablanca

10.1136/oemed-2018-ICOHabstracts.843

North Africa mainly includes Egypt, Libya, Tunisia, Algeria, Morocco and on top of that Mauritania. 210 million people live there. The average GDP per capita is $3513 \$$, while the world's average sits around 14956 \$, and the economical growth doesn't exceed 3\%.

Occupational health is directly linked to the social environment and to the company's performance, it can also impact prevention policies, management of critical circumstances and 
daily practices. Most of the time, human resources contributors don't include new occupational health managerial, strategic nor legal stakes in the process of managing companies in African countries.

The lack of human resources in the field of occupational health in these countries, enforces us to coordinate efforts to establish practical programs allowing us to address basic occupational health issues. A unique repository for occupational physicians, nurses, engineers and managers should be implemented, either during initial or continuing training. We should build an occupational health training network by creating links between different actors in all these countries. All those occupational health actors should be certified by an independent organisation.

The exchange and adjustment of experiences as well as the sharing of means, will enable us, both in short and medium term, to use occupational health as a performance lever for our companies.

\section{$1711 \mathrm{~b}$ INRS AND INTERNATIONAL COOPERATION}

S Pimbert. INRS - France

\subsection{6/oemed-2018-ICOHabstracts.844}

The INRS, national institute of research and security, established in 1947, has the task of preventing workplace accidents and occupational diseases in France.

It gathers 600 permanent workers, with 80 million euros as an annual budget.

Its operating modes are:

- Studies and researches

- Support for companies

- Training

- Information and communication

At an international level, the INRS participates in ISSA works, mainly with the research and chemistry committee, the ILO and the WHO. It plays a part in CIST/ICOH works. It also elaborates cooperation projects with organisations such as the NIOSH (USA), IRSST (Quebec), IFA (Germany), KOSHA (South Korea), and IST (Switzerland).

The INRS is a part of the PEROSH network that includes major research organisations in the field of occupational health in Europe.

The INRS is also a part of the EUROSHNET network, which is a network of European normalizers.

About the francophone cooperation, the INRS established many cooperation projects like with the ISST (Tunisia), faculty of medicine of Casablanca, Mediterranean and Tunisian society of occupational medicine.

\section{C OSH INSTITUTIONS NETWORKING IN NORTH AFRICA: A ROUTE TO IMPLEMENT SDG}

H Hamzaoui. OSH specialist for North Africa- ILO office for MAGHREB Algiers

10.1136/oemed-2018-ICOHabstracts.845

The General Assembly of the United Nations adopted the Sustainable Development Goals for 2030 in 2015. These 17 goals target the eradication of poverty, protection of the planet and the guarantee of prosperity for all within the framework of a new sustainable development agenda. Goal 8; Decent Work and Economic Growth; aims to implement the principles of decent work, including optimal working conditions for all, enabling protection of human capital and inclusive economic development.

Through cooperation and linkages between the various occupational health and safety networks and institutions, North African countries would improve their inherent capacities to meet the targets of Objective 8, including the reduction of related work accidents and diseases. Networking would make it possible to pool human and material resources (often missing), complementarity of expertise, exchange of best practices and comparability of indicators in a similar socio-economic environment.

Improved OSH cooperation between North African countries will improve the achievement of sustainable development objectives and enable the different social partners to honour their commitment to this goal.

\section{$1711 \mathrm{~d}$ THE PLACE OF COOPERATION IN THE EVOLUTION OF OCCUPATIONAL MEDICINE IN TUNISIA}

R Gharbi. Industrial toxicology research lab, Faculty of medicine of Tunis

\subsection{6/oemed-2018-ICOHabstracts.846}

Since its independence in 1958, Tunisia never ceased confirming its political will to protect worker's health by issuing successive and specific legislative and regulatory texts. However, the achievement of this objective didn't really arise until 1978 thanks to the establishment of the training course for occupational medicine specialists at the faculty of medicine of Tunis, after benefiting from north-south cooperation programs particularly with France, Belgium and Canada. That's how we have now 40 specialised instructors (Prof, MCA, AHU) distributed in four medical schools in Tunisia, 50 labour doctor inspectors, 60 labour medical advisors at the CNAM and 1000 occupational doctors in different companies. Furthermore, the country has a research facility specialised in industrial toxicology, an occupational health and safety institute and a national council for preventing professional hazards which gathers all contributors in the field of occupational health and safety.

As a consequence, occupational medicine in Tunisia got through its creation stage and is currently oriented towards promoting local and international cooperation in many fields, particularly in multilateral research and in enhancing specific axes of the specialty.

\section{1e 1992-2017, A QUARTER CENTURY OF INTERNATIONAL PARTNERSHIP FOR PROMOTING OCCUPATIONAL HEALTH IN MOROCCO}

A El Kholti. Occupational Health Unit, Faculty of Medicine and Pharmacy, University Hassan II of Casablanca

\subsection{6/oemed-2018-ICOHabstracts.847}

Over the last 25 years, the Occupational Health Unit (USAT) of the Faculty of Medicine and Pharmacy of Casablanca, the only university structure dedicated to occupational health in 